\title{
O JOGO XADREZ JAPONÊS MATRICIAL
}

Luana Beatriz Cardoso', Vanessa de Freitas Travello', Roger Gomes Soares da Silva ${ }^{1}$, .Antonio Carlos Tamarozzi $^{2}$

Universidade Federal de Mato Grosso do Sul - Campus de Três Lagoas. ${ }^{1}$ Aluno do Curso de Matemática - bolsista do Grupo PET Matemática / CPTL / UFMS. ${ }^{2}$ Tutor do Grupo PET Matemática / CPTL/UFMS. E-mail: luhbeatriz93@gmail.com

\section{RESUMO}

Este trabalho tem o objetivo de apresentar o jogo matemático Xadrez Japonês Matricial, desenvolvido durante as atividades cotidianas do grupo PET Matemática da UFMS de Três LagoasMS, junto a escolas publicas da região. O jogo proposto é uma variação do xadrez japonês, capaz de propiciar o desenvolvimento do raciocínio lógico dedutivo e lateralidade, uma vez que é disposto em linhas e colunas fazendo analogia a uma tabela. Deste modo, a proposta do jogo Xadrez Japonês Matricial, reforça a afirmação de Guzmán (1989) de que o jogo não tem apenas o objetivo de divertir, mas sim, de extrair das atividades, materiais suficientes para gerar conhecimento, interesse e fazer com que os alunos pensem com certa motivação. $O$ trabalho foi fruto de uma pesquisa de cunho qualitativo e descritivo, sendo os resultados quantitativos aferidos a partir das notas dos estudantes do ensino básico da escola atendida, que apontaram melhora significativa no seu valor absoluto.

Palavras-chave: Ensino de Matemática, Raciocínio Lógico, Jogos Matemáticos, Matrizes.

\section{INTRODUÇÃO}

A diversidade de estudantes atualmente atendidos no ensino básico, associada a pluralidade de experiências adquiridas, exigem o ensino de Matemática com um maior dinamismo, capaz despertar o interesse e incentivar o progresso na ciência. Neste sentido, foram explorados e discutidas ações que promovam o ensino inovador, destacando abordagens que valorizam o lúdico, a criatividade e o vínculo com a prática diária dos estudantes.

Conforme a obra de NOT (2003) “ (...) toda atividade requer um dinamismo, uma dinâmica, que se define por dois conceitos: o de energia e de direção". Neste sentido, descrevemos no trabalho um jogo, denominado xadrez japonês matricial que permite associações matemáticas importantes para a aprendizagem de conteúdos matemáticos. No desenvolvimento do jogo priorizou-se a abordagem lúdica do assunto de matrizes, recorrente para os alunos do ensino básico. Este recurso visa a introdução de tabelas nas séries iniciais até a introdução de conceitos relacionados as matrizes e operações com matrizes, para alunos do ensino médio.

O jogo xadrez japonês matricial pode ser utilizado como recurso complementar ao ensino de matemática, contribuindo para o desenvolvimento competências como: entendimento 
posicional de números dispostos em uma tabela, entendimento concreto de elementos principais de uma tabela: linha, coluna e diagonal. Especificamente para o ensino médio, estas competências são estendidas para o caso de matrizes, onde é possível explorar propriedades subjacentes a este conceito matemático.

Este trabalho propõe investigar o impacto que um recurso lúdico, no caso um jogo que envolve atividades numéricas e posicionais, exerce sobre a aprendizagem de competências relacionadas a Matemática.

\section{METODOLOGIA}

O método desenvolvido neste trabalho aponta para o desafio de buscar estratégias de apresentação de conteúdos matemáticos, associados com desafios interativos, com recurso rico em estímulos audiovisuais, para motivar o aluno em direção à busca pelo aprendizado, como sugere Moratori (2003) “Um jogo para ser útil no processo educacional, deve promover situações interessantes e desafiadoras para a resolução de problemas, permitindo aos aprendizes uma auto avaliação quanto aos seus desempenhos".

Descreveremos a construção e o funcionamento do jogo para entendermos o processo e os benefícios diretos que o mesmo pode propiciar na aquisição de habilidades matemáticas, que constituem os aspectos investigados nesta pesquisa. Esta etapa é primordial, haja vista que as estratégias de jogo utilizadas, implicam na análise da eficácia do objetivo proposto.

Deve ser destacado que a construção do jogo é completamente artesanal, cuja montagem requer materiais de fácil acesso: papelão, cola quente, caneta permanente, E.V.A, palitos de fosforo, palitos de picolé, clips, estilete, fita durex, papel cartão, tecido aderente, lápis, alicate e tesoura. Sobre a placa de papelão, que pode ser um fundo de caixa grande, são dispostos espaços, preferencialmente circulares, que permitem encaixes de números.

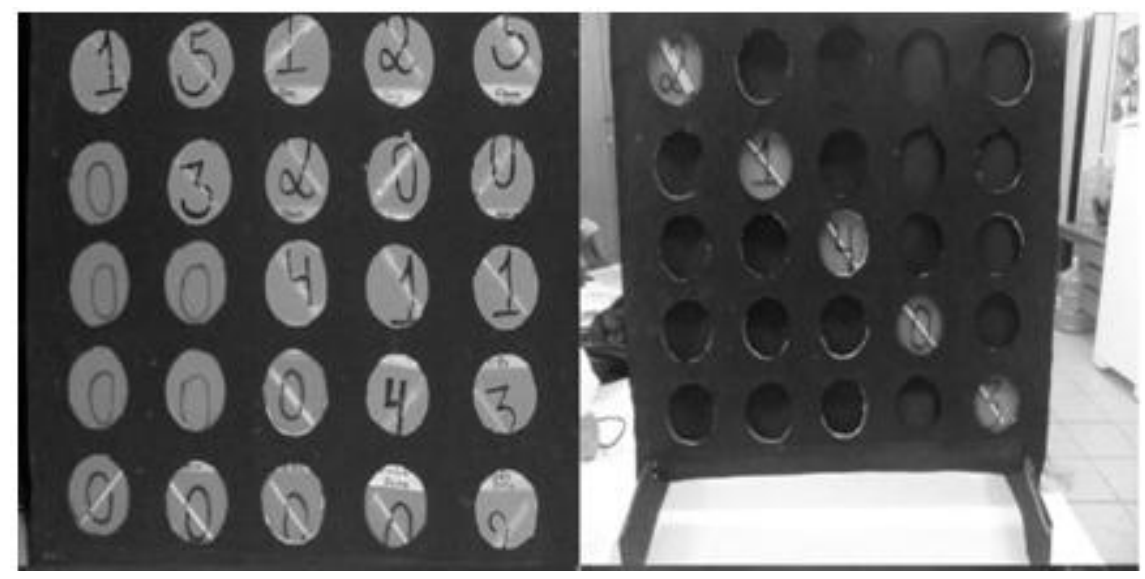

Figura 1. Jogo montado 
A quantidade destes espaços pode variar conforme o objetivo proposto, no modelo da figura cima, é ilustrado a construção de uma disposição tabular quadrada com 5 linhas e 5 colunas. Tais espaços são preenchidos com círculos feitos em E.V.A que deve abranger uma variedade suficientemente grande dos algarismos de 0 a 9 e em duas cores. Ou ainda, para efeito de utilização no ensino médio, podem ser preenchidos com elementos $a_{i j}$ que descrevem o comportamento posicional da linha i em interseção com a coluna j. Observa-se que, no modelo acima os palitos de picolé são utilizados com a finalidade de fixação dos circulos no espaços, bem como para caracterizar a estrutura da disposição diagonal de uma tabela ou matriz.

O jogo pode ser utilizado individualmente ou em grupo, não necessariamente em caráter de disputa. De fato, apresentamos a seguir algumas, dentre muitas situações exploratórias do mesmo:

1) O lado esquerdo da figura acima, mostra uma disposição tabular conhecida como diagonal, pois foram preenchidas somente posição que classificam este formato.

2) O lado direito da figura acima, mostra uma disposição tabular conhecida como diagonal superior, pois somente os elementos acima da diagonal são elementos não nulos. De maneira similar, pode ser construído disposições tabulares diagonais inferiores.

3) A figura a seguir ilustra as disposições matriciais conhecidas como matrizes linhas e matrizes colunas, que podem ser visualizadas tapando-se as demais disposições tabulares:

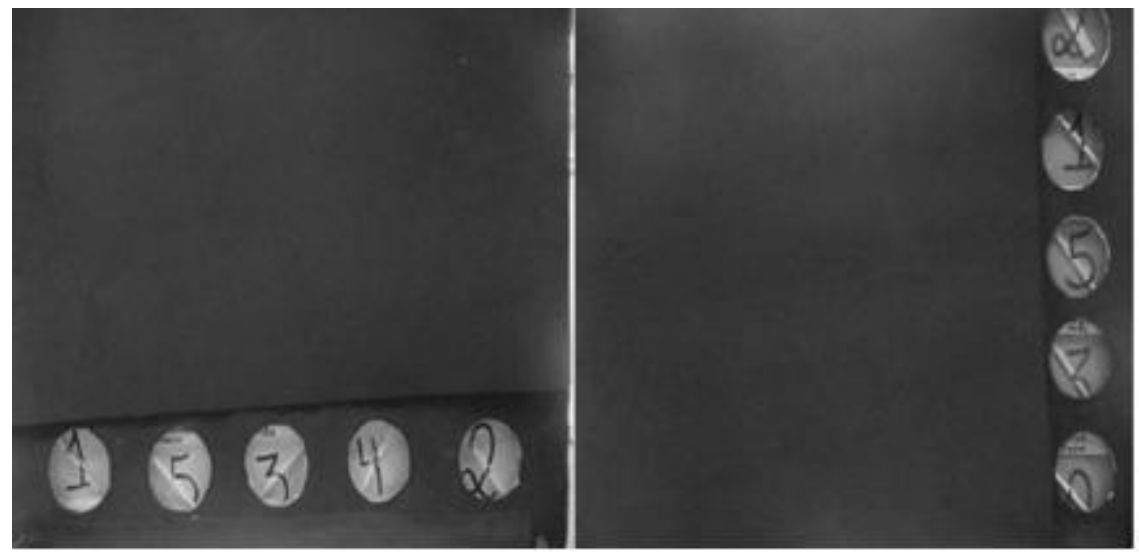

Figura 2. Matriz linha e matriz coluna

4) A habilidade de entender a estrutura posicional dos elementos em uma tabela ou então de visualizar concretamente a representação dos elementos $a_{i j}$ que formam uma 
matriz, pode ser facilitado com o envolvimento do aluno no preenchimento dos espaços. A figura a seguir, ilustra dois momentos com a utilização desta abordagem:

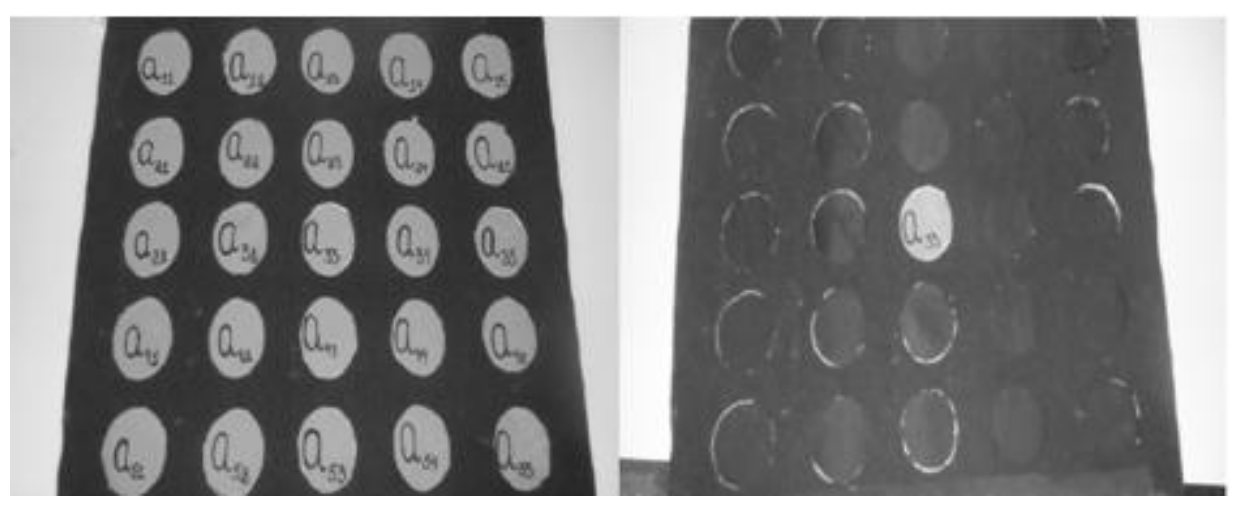

Figura 3. Posição dos elementos em uma tabela ou matriz

5) Com a tabela inteiramente preenchida, o professor pode solicitar a solução de pequenos desafios: determinação de submatrizes, ou seja matrizes componentes da matriz maior, calculo de determinantes e escalonamentos.

6) Em se tratando de caráter de disputa, o jogo pode ser disputado entre duas equipe de alunos, cujo propósito é preencher o quadro tabular com elementos consecutivos de mesma cor. Os jogadores devem formar uma linha ou uma coluna, ou uma diagonal com círculos da mesma cor, independente dos algarismos. Ganha aquele que completar primeiramente a disposição com 4 peças de mesma cor. Para assegurar a vitória é exigido do aluno exercitação, a orientação e organização posicional dos elementos na tabela.

A partir das situações exploratórias do jogo, destacadas acima, os bolsistas do programas de ensino tutorial (PET), vinculados ao curso de licenciatura em Matemática da Universidade Federal de Mato Grosso do Sul, estudaram e desenvolveram sequencias didáticas que poderiam ser aplicadas a alunos do ensino básico, com vistas ao desenvolvimento de habilidades matemáticas relacionadas a posição de elementos em uma disposição tabular ou matricial, propriedades e inferências.

Foram duas frentes de atuação com objetivos, e portanto estratégias de aprendizagem distintas. Para o ensino fundamental foi priorizado o uso do jogo xadrez japonês matricial, objetivando habilidades de reconhecimentos de posições de elementos em uma tabela, 
classificação em subtabelas, dentre outros, enquanto que, para o ensino estas competências são estendidas para o caso de matrizes, onde é possível explorar propriedades subjacentes a este conceito matemático.

\section{RESULTADOS E DISCUSSÃO}

A metodologia de estudo desenvolvida com os alunos da escola atendida, a partir da aplicação das sequencias didáticas acima, demonstrou que o jogo xadrez japonês matricial, foi um elemento motivador para a introdução de conceitos matemáticos relevantes e necessários para a formação básica do indivíduo. Com efeito, esta afirmação é baseada nos depoimentos dos alunos participantes do projeto, bem como no reconhecimento, por parte de seus professores, da melhora da participação e desempenho dos mesmos em sala de aula. Esta observação corrobora com a afirmação de Grando (2001): “(...) ao observar o comportamento de uma criança enquanto joga, pode-se perceber o quanto ela desenvolve sua capacidade de fazer perguntas, de buscar diferentes soluções, de repensar situações, de avaliar suas atitudes, elaborar estratégias, encontrar e reestruturar novas relações, arriscar soluções e depurá-las, enfim, resolver problemas".

A boa receptividade do jogo pelos alunos atendidos teve reflexos diretos para o interesse da turma acerca dos conteúdos abordados. A comparação das notas entre os semestres anterior e posterior a realização das atividades na escola, mostram um progresso significativo na aprendizagem de conteúdos relacionados ao jogo, mas também no aproveitamento escolar de outras competências matemáticas desejáveis.

Os parâmetros curriculares nacionais para a Matemática na educação básica abordam minimamente a utilização dos jogos como um recurso em sala de aula. Desta forma, a apresentação dos resultados com o jogo xadrez japonês pode colaborar na reversão desta tendência, haja vista que exemplifica a observação positiva dos jogos como recurso pedagógico para uma aprendizagem mais significativa.

\section{CONCLUSÃO}

O ensino de Matemática nas escolas brasileiras passa pelo desafio de vencer as estatísticas que registram o desempenho insatisfatório dos alunos nos mais diversos níveis de ensino. Neste sentido, os professores são também desafiados a buscar alternativas metodológicas que assegurem uma aprendizagem significativa dos seus alunos. 
A apresentação não meramente conteú dista, mas de maneira lúdica, normalmente motiva o aluno, que se sente participante e comprometido com as regras para chegar à solução do jogo proposto, onde ele pode realizar ações concretas, observar os resultados de suas ações e refletir sobre os erros para propor novas soluções.

Apresentamos neste trabalho um jogo matemático e algumas estratégias de ensino a ele vinculadas, que exigem concentração e organização por parte do aluno. O jogo pode ser aplicado nos dois níveis do ensino básico, onde são exploradas representações que exigem a disposição posicional de elementos como também suas representações, estimulando o desenvolvimento de habilidades matemáticas importantes para o desenvolvimento da cidadania.

Sabe-se que, de fato, é um desafio superar a didática da mera transmissão/assimilação do conhecimento, ligada a uma concepção tradicional de ensino e atuar de forma crítica numa perspectiva dialética, visando à mudança na forma de pensar, promovendo o aprender de forma reflexiva, que promova a autonomia e a cidadania. Foi possível observar que num prazo curto de tempo, os alunos da escola atendida conseguiram se apropriar de alguns conceitos matemáticos fundamentais para a compreensão dos conteúdos da disciplina. Uma questão positiva é que, o professor ao ver a satisfação da turma se encorajou e começou a propor novos jogos planejandoos de acordo com os conteúdos previstos no currículo da disciplina.

\section{REFERÊNCIAS}

BRASIL. Ministério da Educação. Secretaria de Educação Fundamental. Parâmetros Curriculares Nacionais: Matemática. (3ํ e 4o ciclos do ensino fundamental). Brasília: MEC, 1998.

BRASIL. Ministério da Educação. Secretaria de Educação Média e Tecnológica. Parâmetros Curriculares Nacionais (Ensino Médio). Brasília: MEC, 2000.

GRANDO, R. C, O jogo na educação: aspectos didático-metodológicos do jogo na educação matemática. Unicamp, 2001.

GUZMÁM, M. Tendências Actuales de la Enseñanza de la Matemática, Studia Pedagógica, Revista de Ciencias de la Educación, vol. 21, pp 19-26, 1989.

MORATORI, P. B. Por que utilizar jogos educativos no processo de ensino aprendizagem. Trabalho de conclusão da disciplina introdução a informática na educação, no Mestrado de Informática aplicada à Educação da Universidade Federal do Rio de Janeiro, 2003.

NOT, L. As pedagogias do conhecimento. São Paulo: DIFEL, 1993. 